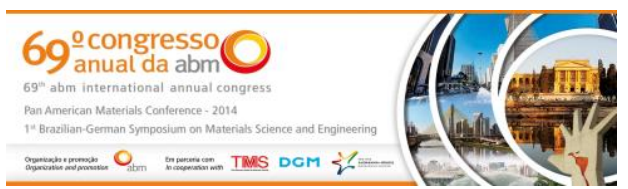

Tema: Mecânica de Fratura e Integridade Estrutural

\title{
CARACTERIZAÇÃO ESTRUTURAL E MECÂNICA DE CHAPAS EXPANDIDAS CONFECCIONADAS A PARTIR DE AÇOS FERRÍTICOS*
}

\section{Resumo}

\author{
Henrique Gobbi Soares ${ }^{1}$ \\ Geraldo Lúcio de Faria ${ }^{2}$ \\ Leonardo Barbosa Godefroid ${ }^{3}$ \\ Paulo Sérgio Moreira ${ }^{4}$ \\ Joner Oliveira Alves ${ }^{5}$
}

Chapas expandidas são conhecidas como um material metálico com orifícios em forma de losango, cuja produção ocorre em uma máquina que utiliza corte sobre pressão e processos de alongamento para transformar chapas em metal expandido. Estas chapas são usualmente fabricadas em aço carbono, mas em função de serem susceptíveis a fenômenos de corrosão, estudos têm sido conduzidos com o objetivo de se avaliar a viabilidade de substituição destes aços comuns por inoxidáveis. Este trabalho consistiu em caracterizar e testar mecanicamente amostras representativas de chapas expandidas de aços inoxidáveis ferríticos (AISI 410D e AISI 444A) e uma de aço carbono ABNT 1010 com espessura superior às demais. A caracterização estrutural revelou que as estruturas de todas as amostras são influenciadas pelo processo de expansão, apresentando grãos com níveis de deformação e encruamento predominantemente nas hastes. Observou-se a presença de inclusões em diferentes níveis em todas as amostras analisadas, sendo os maiores níveis verificados no aço ABNT 1010. Os resultados obtidos mostraram que as chapas expandidas confeccionados de aços inoxidáveis apresentaram os melhores índices de resistência mecânica quando comparadas à chapa de aço ABNT 1010, mesmo este possuindo maior espessura.

Palavras-chave: Chapas Expandidas; Aços Inoxidáveis Ferríticos; Ensaios Mecânicos.

\section{STRUCTURAL AND MECHANICAL CHARACTERIZATION OF FERRITIC STAINLESS STEEL EXPANDED SHEETS}

\begin{abstract}
Expanded sheets are commonly known as metallic component with holes with diamond shapes. They are produced in a machine that uses cutting under pressure and strain process to transform common sheets is expanded components. These sheets are usually manufactured with ordinary carbon steel, but as they are susceptible to corrosion phenomenon, studies have been carried aiming to evaluate the viability of substitution of ordinary steels by stainless steel. This work proposed to characterize and to apply mechanical tests in expanded sheets made by ferritic stainless steels (AISI 410D and AISI 444) and compare the results with an expanded sheet made by ABNT1010 steel with higher thickness. The structural characterization showed that expanded sheets structures are influenced by the expansion process. It were observed deformed ferritic grains in all structure, strongly in rod area. Different inclusions levels in all studied samples were observed. The obtained results showed that stainless steel expanded sheets presented the better indexes of mechanical strength compared to the ABNT1010 expanded sheet.

Keywords: Expanded Sheets; Ferritic Stainless Steel, Mechanical Tests.

\footnotetext{
Graduando em Engenharia Metalúrgica, Universidade Federal de Ouro Preto, Ouro Preto, MG, Brasil. Físico, Dr., Professor, DEMET, Universidade Federal de Ouro Preto, Ouro Preto, MG, Brasil.

Engenheiro, Dr., Professor, DEMET, Universidade Federal de Ouro Preto, Ouro Preto, MG, Brasil. Brasil.
}

Engenheiro, MSc., Técnico Administrativo, DEMET, Universidade Federal de Ouro Preto, Ouro Preto, MG,

5 Físico, Dr., Pesquisador, Aperam South America, Timóteo, MG, Brasil.
\end{abstract}

\footnotetext{
* Contribuição técnica ao 69 Congresso Anual da ABM - Internacional e ao 14ํㅡㄹ ENEMET - Encontro Nacional de Estudantes de Engenharia Metalúrgica, de Materiais e de Minas, 21 a 25 de julho de 2014, São Paulo, SP, Brasil.
} 


\section{INTRODUÇÃO}

Em qualquer setor industrial, em especial o sucroenergético e o petrolífero, a redução das paradas para manutenção de equipamentos é fator preponderante para uma usina de alta produtividade. A aquisição de peças de reposição, o custo com a mão-de-obra especializada e o tempo de parada na produção são fatores que consomem uma parte significativa da rentabilidade da usina.

Geralmente, os equipamentos dos mais diversos setores industriais estão submetidos a esforços mecânicos e a ambientes corrosivos. Por este motivo, peças fabricadas em aço carbono precisam ser frequentemente substituídas. Neste contexto, o emprego dos aços inoxidáveis na fabricação de alguns componentes estabeleceu-se como importante alternativa para um decréscimo na perda específica por corrosão [1-3].

Uma importante aplicação a ser desenvolvida para os aços inoxidáveis e, ainda pouco estudada, é a fabricação de chapas expandidas. As chapas expandidas consistem em chapas de aço que são submetidas a procedimentos de corte e repuxo mecânico sendo, transformadas em telas rígidas, inteiriças e uniformes. As chapas expandidas, quando comparadas a chapas convencionais, proporcionam um menor custo por área de produto final. Com grande variedade de malhas que vão desde a microexpandida, utilizadas para elementos filtrantes, até as mais pesadas, empregadas em pisos industriais, as chapas expandidas podem ser usadas em várias aplicações, entre elas: grades, portões, proteção de equipamentos, cestos para lixo, porta-revistas, filtros, pisos, escadas, móveis e divisórias, bancos e componentes de móveis, guarda-corpos e sacadas, protetores de portas e janelas, dutos e calhas para cabos elétricos, tetos e forros na construção civil, entre outras [4].

Atualmente, as chapas expandidas especificadas para aplicações mais robustas, como as exemplificadas no parágrafo anterior, são, em sua grande maioria, fabricadas a partir de aços carbono como ABNT 1010 ou ABNT 1020. Esta seleção de materiais vem sendo, ao longo dos anos definida em função unicamente do atendimento dos pré-requisitos de propriedades mecânicas e do baixo custo destes materiais. Entretanto, estudos vêm mostrando que, a médio e longo prazo, o número e os intervalos de tempos de paradas para manutenção e substituição das chapas expandidas fabricadas a partir dos aços carbono comuns têm tido grande peso sobre a relação custo/benefício da utilização destes materiais, aumentando-a, principalmente em setores como o sucroenergético e o petrolífero, onde estas chapas trabalham sob condições extremamente agressivas (corrosão, temperaturas e pressões elevadas, elevados níveis de solicitação mecânica, oscilações mecânicas, entre outros) [5].

Neste contexto, a classe dos aços inoxidáveis se apresenta como uma potencial candidata para a substituição dos aços carbono em aplicações que envolvam a utilização de chapas expandidas de alta resistência mecânica em ambientes corrosivos [6,7]. O presente trabalho teve como objetivo propor uma metodologia experimental que possibilitou comparar as características mecânicas e estruturais de chapas expandidas confeccionadas a partir dos aços inoxidáveis ferríticos AISI 410D e AISI 444A, ambas com espessura de $4,5 \mathrm{~mm}$, com as das chapas expandidas de aço carbono ABNT 1010 com espessura de 5,5mm.

Como não existem normas internacionais estabelecidas para a realização de ensaios mecânicos em chapas expandidas e a diferença de espessura entre as mesmas tem uma forte influência comercial, não podendo ser desprezada, este

* Contribuição técnica ao 69 Congresso Anual da ABM - Internacional e ao 14ํㅡㄹ ENEMET - Encontro Nacional de Estudantes de Engenharia Metalúrgica, de Materiais e de Minas, 21 a 25 de julho de 2014, São Paulo, SP, Brasil. 


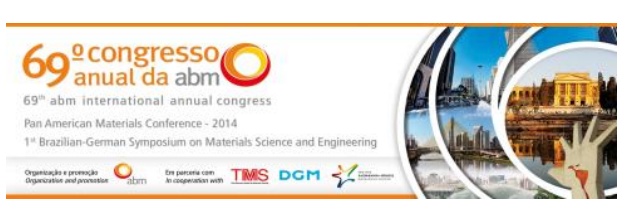

trabalho tem um forte caráter de ineditismo no que diz respeito a metodologia experimental, assim como é um importante indicador sobre a possibilidade de substituição de materiais na fabricação de chapas expandidas.

\section{MATERIAIS E MÉTODOS}

\subsection{Materiais}

Foram retiradas amostras de chapas expandidas confeccionadas industrialmente a partir dos aços inoxidáveis AISI 410D e AISI 444A e do aço carbono ABNT 1010. As análises químicas dos materiais foram realizadas nas instalações da Empresa APERAM e os dados são apresentados na Tabela 1.

Tabela 1. Composição química dos materiais utilizados (\% em massa).

\begin{tabular}{c|cccccccccc} 
& \multicolumn{10}{|c}{} \\
\hline Aço & $\mathrm{C}$ & $\mathrm{Mn}$ & $\mathrm{Si}$ & $\mathrm{P}$ & $\mathrm{S}$ & $\mathrm{Cr}$ & $\mathrm{Ni}$ & $\mathrm{Mo}$ & $\mathrm{Al}$ \\
\hline 410D & 0,007 & 0,581 & 0,57 & 0,022 & 0,0005 & 11,283 & 0,338 & 0,0065 & 0,002 \\
\hline 444A & 0,009 & 0,206 & 0,53 & 0,021 & 0,0006 & 17,511 & 0,249 & 1,7908 & 0,005 \\
\hline 1010 & 0,09 & 0,472 & 0,01 & 0,014 & 0,0177 & 0,013 & 0,008 & 0,0018 & 0,045 \\
\hline & & & & & Elementos & & & \\
\hline Aço & $\mathrm{Cu}$ & $\mathrm{Co}$ & $\mathrm{V}$ & $\mathrm{Nb}$ & $\mathrm{Ti}$ & $\mathrm{Sn}$ & $\mathrm{W}$ & $\mathrm{B}$ & (ppm) \\
\hline 410D & 0,029 & 0,025 & 0,033 & 0,017 & 0,0034 & 0,0046 & 0,006 & - & 134 \\
\hline $444 \mathrm{~A}$ & 0,038 & 0,023 & 0,046 & 0,164 & 0,1624 & 0,0032 & 0,008 & - & 116 \\
\hline 1010 & 0,011 & 0,001 & 0,0001 & 0,002 & 0,0009 & 0,0032 & 0,074 & 0,0002 & -
\end{tabular}

As amostras foram cortadas na Empresa APERAM e recebidas com dimensões reduzidas para a realização deste trabalho. A Figura 1 apresenta fotografias das amostras no estado de entrega. As chapas expandidas fabricadas a partir dos aços inoxidáveis tinham espessura de $4,5 \mathrm{~mm}$ e as de aço carbono 5,5mm.
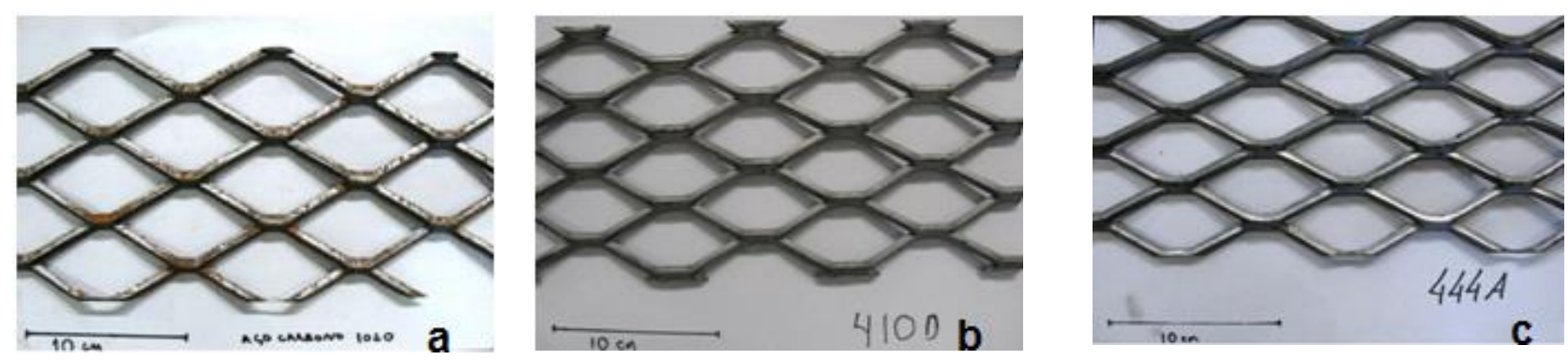

Figura 1. Fotografias das chapas expandidas nos seus estados de entrega (a) ABNT 1010 178x305mm; (b) AISI 410D - 143x301mm; (c) AISI 444A - 151×300mm.

\footnotetext{
* Contribuição técnica ao 69ำ Congresso Anual da ABM - Internacional e ao 14ํㅡㄹ ENEMET - Encontro Nacional de Estudantes de Engenharia Metalúrgica, de Materiais e de Minas, 21 a 25 de julho de 2014, São Paulo, SP, Brasil.
} 


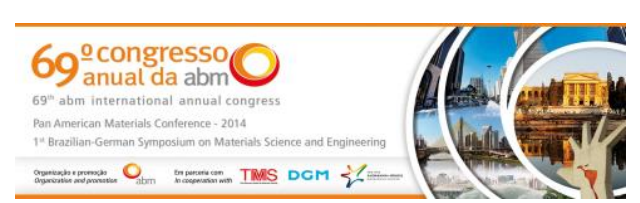

de metalurgia do IFMG-OP. A geometria complexa das chapas expandidas torna procedimentos de medições das áreas transversais em tempo real uma operação muito complicada e imprecisa, sendo assim optou-se por registrar e trabalhar com gráficos do tipo força versus alongamento até a fratura da amostra e não com as curvas clássicas tensão versus deformação.

Cada uma das amostras ensaiadas sob tração foi submetida a análises fractográficas com o auxílio de um microscópio eletrônico de varredura Inspect 550 do fabricante Fei Company.

Para a realização dos ensaios de dobramento foi utilizada máquina universal de ensaios com capacidade de 10 toneladas, da fabricante Kratos, do laboratório de Ensaios Mecânicos do DEMET-UFOP. Adaptou-se um dispositivo à máquina que permitiu à realização do dobramento a 90, conforme ilustra a Figura 3.

As relações geométricas que forneceram a relação entre o ângulo de dobramento e a distância de rebaixamento do punção são representadas na Figura 4. Observa-se que foram utilizadas relações entre triângulos retângulos e triângulos isósceles, para determinar o ângulo de dobramento $(\theta)$ em função do deslocamento do punção(h).

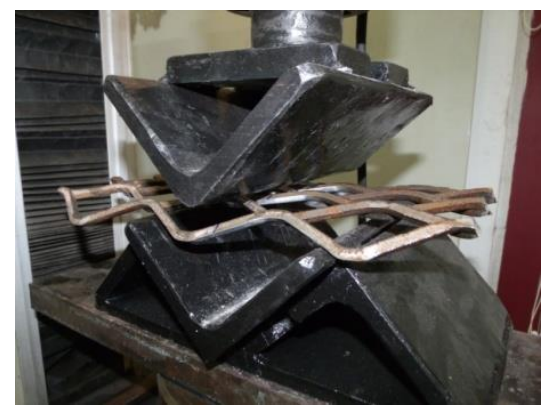

Figura 3. Montagem do ensaio de dobramento.

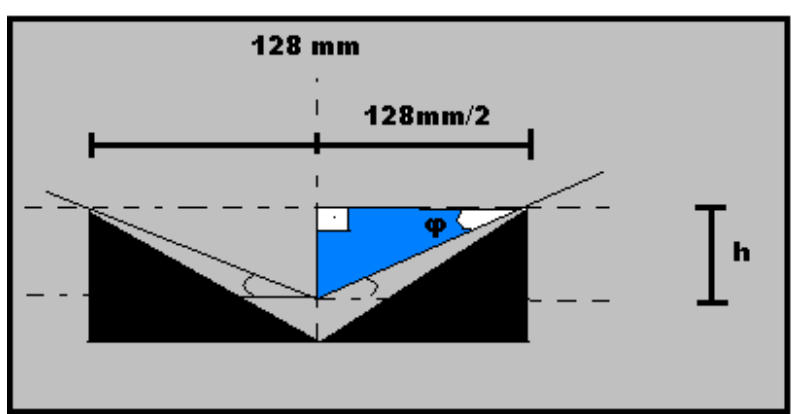

Figura 4. Relações utilizadas para obtenção do ângulo de dobramento.

O acoplamento do dispositivo na máquina permitiu que fosse calculada a variação do ângulo de dobramento em função da carga aplicada. As relações algébricas necessárias para a realização da conversão são representadas pelas Equações 1, 2, 3 e 4.

$$
\begin{aligned}
& \theta=2 \times \varphi \\
& \tan \varphi=\frac{h}{\frac{128}{2}} \\
& \varphi=\tan ^{-1} \frac{2 \times h}{128} \\
& \theta=2 \times \tan ^{-1} \frac{2 \times h}{128}
\end{aligned}
$$

O padrão também estabeleceu o local onde o punção exerceria o esforço de dobramento. Após alguns testes foi estabelecido que o ponta do punção deveria imprimir um esforço sobre uma secção que possuísse apenas hastes e não nós, pois verificou-se que quando o esforço de dobramento era exercido sobre os nós os estados de tensões resultantes sobre as amostras implicaria no dobramento de secções das hastes, não permitindo que a secções que apresentavam nós fossem dobradas.

Após o dobramento a $90^{\circ}$, as amostras foram inspecionadas e analisadas quanto à presença ou não de defeitos, assim como os defeitos foram caracterizados. as amostras dobradas de $90^{\circ}$ foram então encaminhadas para a máquina universal de ensaios da fabricante Amsler, para a realização do dobramento a $180^{\circ}$ (dobramento

\footnotetext{
* Contribuição técnica ao 69ำ Congresso Anual da ABM - Internacional e ao 14ํㅡㄹ ENEMET - Encontro Nacional de Estudantes de Engenharia Metalúrgica, de Materiais e de Minas, 21 a 25 de julho de 2014, São Paulo, SP, Brasil.
} 


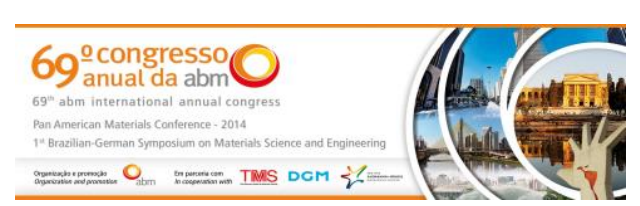

sobre si próprio). As amostras foram novamente inspecionadas em relação à presença ou não de defeitos.

\section{RESULTADOS E DISCUSSÃO}

\subsection{Caracterização Estrutural}

As microestruturas das seções transversais dos aços estudados estão apresentadas na Figura 5. Neste artigo, optou-se por apresentar apenas a seção transversal, pois era nela que se apresentavam os efeitos da deformação plástica decorrente do processo de fabricação das chapas sobre a morfologia dos grãos.

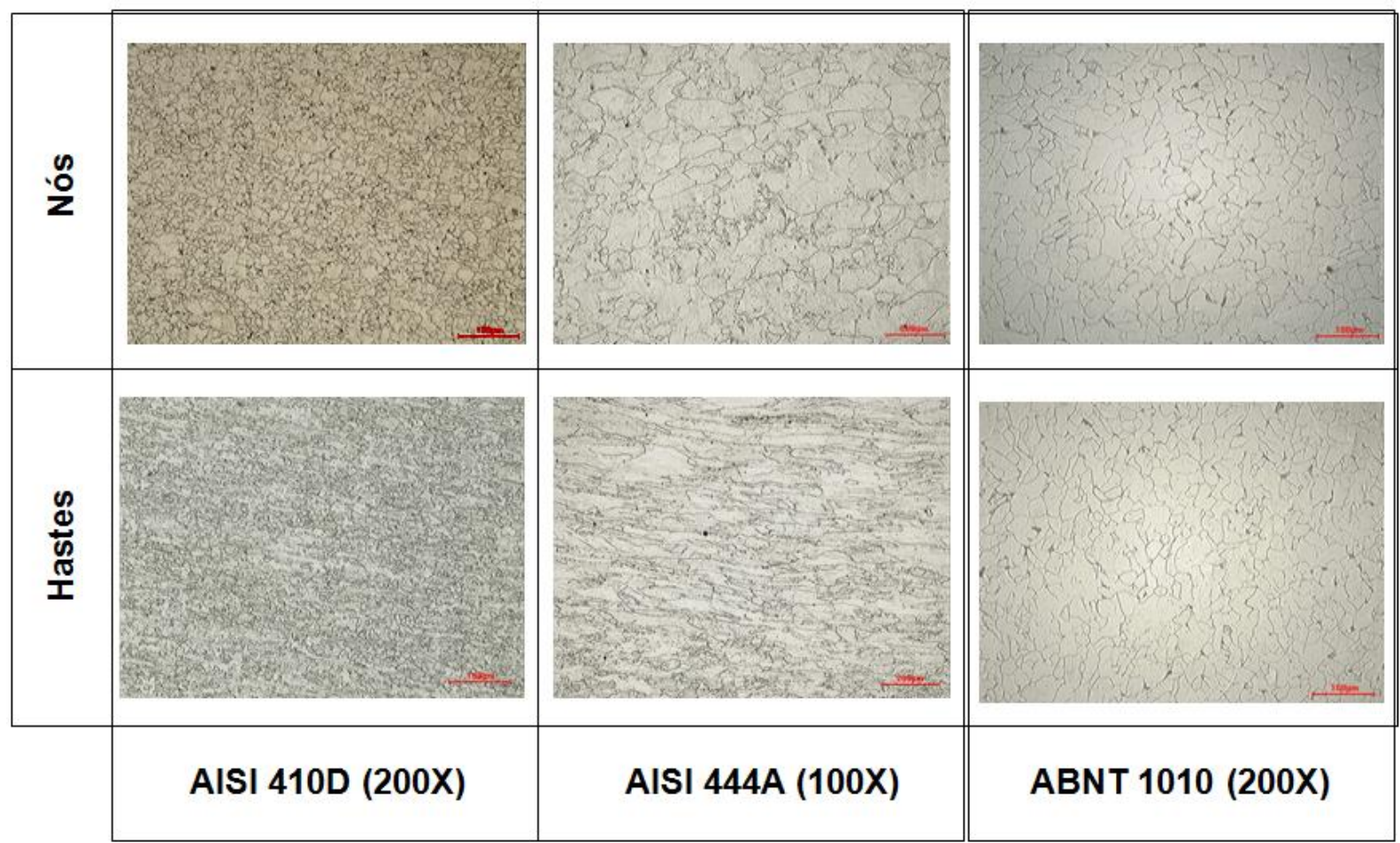

Figura 5. Microestruturas das seções transversais das hastes e dos nós dos aços estudados.

Os resultados indicam que as diferentes chapas expandidas apresentam estruturas distintas. Não foram observadas alterações significativas entre as hastes e os nós quando analisadas nas mesmas direções. Observou-se que algumas hastes e nós analisados nas mesmas direções, apresentavam estrutura bandeada.

Considerando os tamanhos dos grãos dos materiais, verificou-se que o aço inoxidável AISI 410D possuía estrutura bastante refinada em comparação com os demais materiais, com tamanhos de grãos na faixa de $5 \mu \mathrm{m}$ a $15 \mu \mathrm{m}$. Por outro lado, o aço inoxidável AISI 444A apresentou uma estrutura bastante grosseira, em relação ao outros materiais, com grãos apresentando tamanhos na ordem de $60 \mu \mathrm{m}$ a $80 \mu \mathrm{m}$. Os grãos do aço carbono ABNT 1010 apresentaram uma faixa de tamanho intermediaria, em relação aos demais aços, de $20 \mu \mathrm{m}$ a $35 \mu \mathrm{m}$.

Observou-se grãos alongados nos aços inoxidáveis AISI 410D e AISI 444A, preferencialmente nas direção transversais de suas hastes. As regiões superficiais e longitudinais dos três tipos de aços apresentaram grãos com deformações pouco acentuadas. As microestruturas das diferentes partes dão indícios de que as chapas de aço inoxidável apresentavam grãos alongados, ou estrutura bandeada, na

* Contribuição técnica ao 69 Congresso Anual da ABM - Internacional e ao 14ํㅡㄹ ENEMET - Encontro Nacional de Estudantes de Engenharia Metalúrgica, de Materiais e de Minas, 21 a 25 de julho de 2014, São Paulo, SP, Brasil. 


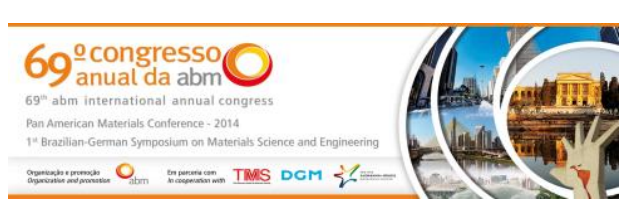

direção de laminação, antes do processo de expansão, e o processo de conformação heterogêneo de expansão ao longo da chapa de todos os materiais favoreceu a presença de grãos com os elevados níveis de deformação, principalmente nas hastes, região muito solicitada durante a confecção das chapas.

\subsection{Ensaios Mecânicos}

A Figura 6 compara as médias e desvios padrão das durezas Vickers $\left(\mathrm{H}_{\mathrm{v}}\right)$ realizadas nas hastes e nós das chapas confeccionadas a partir dos três materiais estudados.

Os resultados mostram que as hastes das distintas chapas expandidas possuem maiores valores de dureza do que os nós das mesmas. Estas diferenças são uma consequência do processo de conformação das chapas (expansão).

Considerando que uma haste é situada entres dois nós, pode-se afirmar que durante a expansão de uma secção da chapa, a ponta positiva da faca incide sobre uma região promovendo um alto grau de fixação entre a ponta da faca e o nó, enquanto o outro nó permanece fixo à chapa, assim sendo o processo de alongamento é direcionado predominantemente nas regiões das hastes, promovendo encruamento e consequentemente maiores durezas.

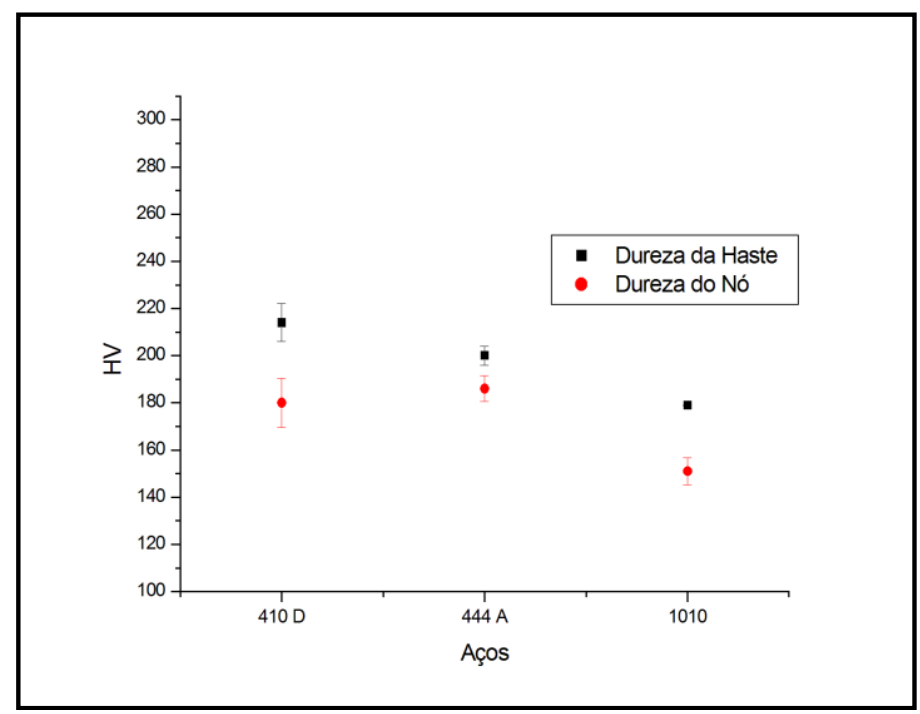

Figura 6. Resultados das médias e desvios padrão das medidas de dureza nos diferentes materiais.

O comparativo das médias das curvas de tração entre os três tipos de aço é apresentado pela Figura 7. Quanto ao desempenho das chapas confeccionadas pelos diferentes materiais, observou que as chapas de aço inoxidável AISI 444A apresentaram maior alongamento e suportaram maiores cargas até a ruptura. $O$ desempenho das chapas de aço inoxidável AISI 410D e de aço carbono ABNT 1010 foram próximos, com uma ligeira superioridade em alongamento e carga de ruptura das chapas de aço inoxidável AISI 410D.

A estricção percentual dos corpos de prova medidos após a fratura das regiões de transição é apresentada na Figura 8. Durante os ensaios de tração foi possível observar que a fratura das chapas ocorre sistematicamente na interseção entre as hastes e os nós que se caracteriza por uma região com severos concentradores de tensão. As superfícies de fraturas dos corpos de prova foram amostradas e analisadas com o auxílio de um MEV. A Figura 9 apresenta as fractografias obtidas, onde é possível observar que o mecanismo de fratura para os três aços estudados é

\footnotetext{
* Contribuição técnica ao 69 Congresso Anual da ABM - Internacional e ao 14ํㅡㄹ ENEMET - Encontro Nacional de Estudantes de Engenharia Metalúrgica, de Materiais e de Minas, 21 a 25 de julho de 2014, São Paulo, SP, Brasil.
} 

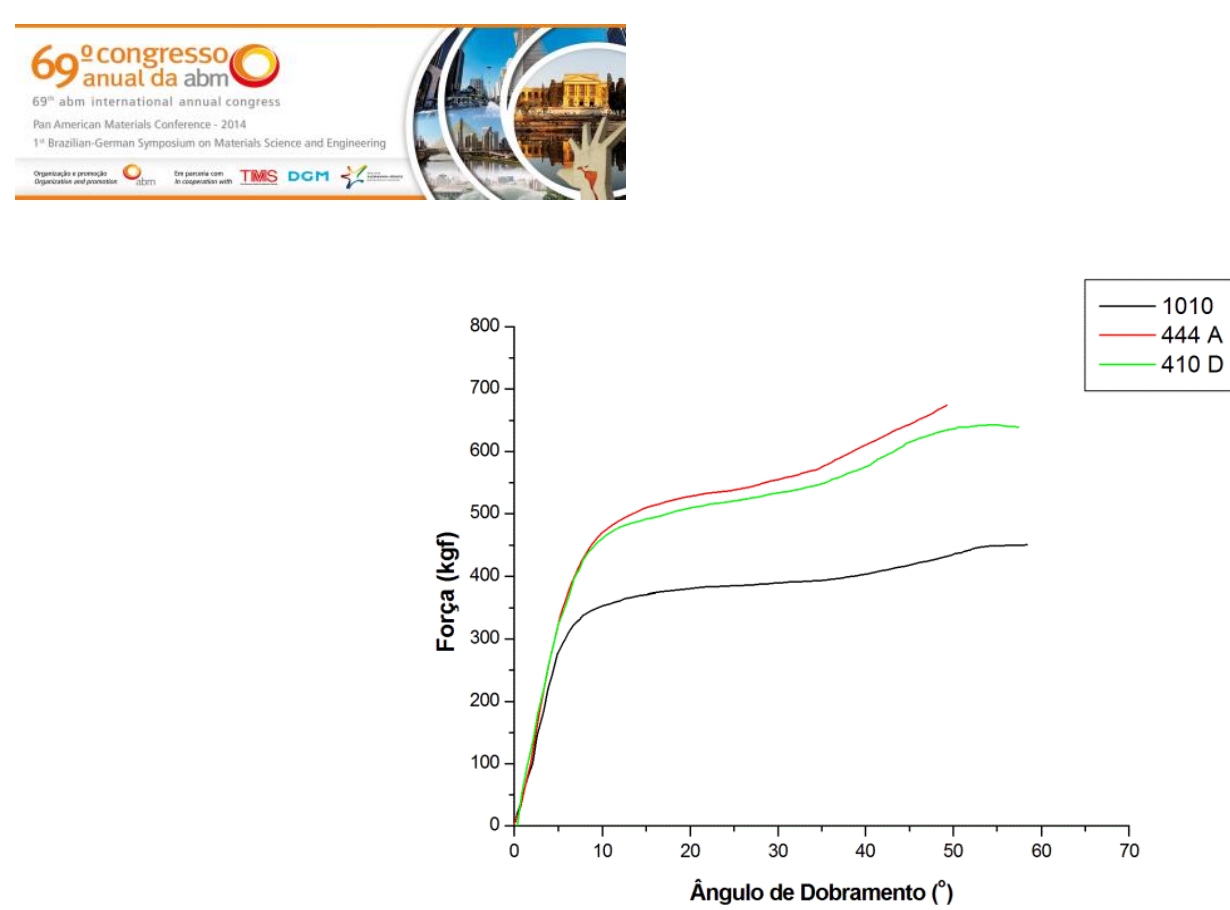

Figura 10. Curvas médias do carregamento versus angulação nas amostras de diferentes chapas.

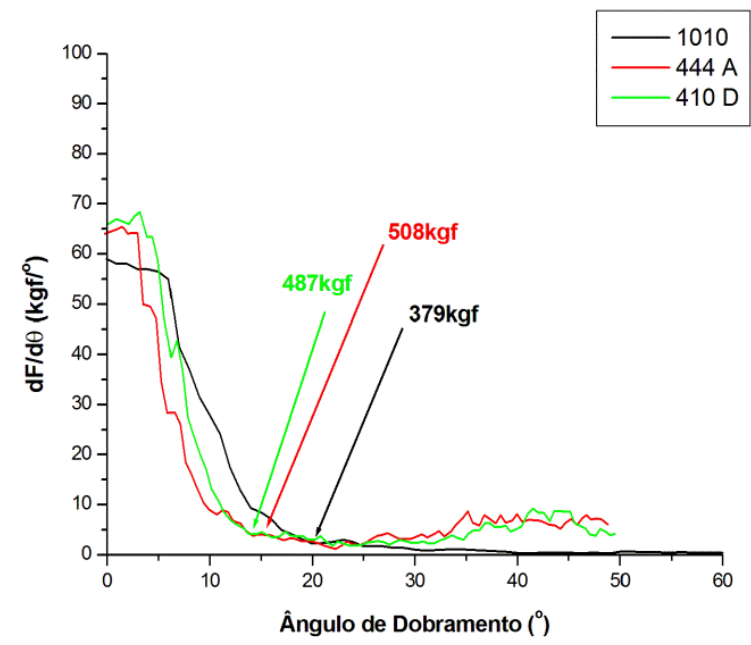

Figura 11. Derivação das curvas médias do carregamento versus angulação nas amostras de diferentes chapas

As derivação da curva de carregamento versus ângulo de dobramento mostra que para o escoamento das amostras de chapas de aço inoxidável AISI 444A é necessário uma carga média de 508kgf e para as amostras das chapas de aço inoxidável AISI 410D é necessário um carregamento em torno de $487 \mathrm{kgf}$. O escoamento em dobramento das duas chapas teve início quando o ângulo de dobramento alcançava valores próximos a $15^{\circ}$.

As amostras das chapas de aço carbono ABNT1010 escoaram em dobramento a uma carga média de $379 \mathrm{kgf}$, a partir de um ângulo de dobramento próximo de $20^{\circ}$, mostrando que esse material suporta um ângulo de dobramento ligeiramente maior e cargas muito menores antes que escoe em dobramento.

Como não se observou nenhum defeito nos corpos de prova dos três materiais nos dobramentos a $90^{\circ} \mathrm{C}$, então eles foram submetidos a dobramento sobre si própria (dobramento a $180^{\circ}$ ), e novamente avaliou-se a presença e características dos defeitos.

As únicas chapas que apresentaram defeitos no dobramento realizado a $180^{\circ}$ foram as amostras das chapas de aço inoxidável AISI 410D. Os defeitos variavam de

\footnotetext{
* Contribuição técnica ao 69 Congresso Anual da ABM - Internacional e ao 14ํㅡㄹ ENEMET - Encontro Nacional de Estudantes de Engenharia Metalúrgica, de Materiais e de Minas, 21 a 25 de julho de 2014, São Paulo, SP, Brasil.
} 
